\title{
Structural Analysis of LP-CM Facing Heat Flux in Tokamak and Evaluation of Stress Field and Displacement Field
}

\author{
Huang-bin Lin, ${ }^{1,2}$ Qi-fang Zeng, ${ }^{3}$ Hai-yuan Qiu, ${ }^{4}$ and Tao Wang ${ }^{2}$ \\ ${ }^{1}$ School of Aerospace Engineering and Applied Mechanics, Tongji University, Si Ping Road, Yangpu District, Shanghai 200092, China \\ ${ }^{2}$ Key Laboratory of Engineering and Technology, Jimei University, Xiamen 361021, China \\ ${ }^{3}$ School of Architecture, Huaqiao University, Ji Mei Street, Jimei District, Xiamen 361021, China \\ ${ }^{4}$ Fujian Monitoring Center of Geological Environment, Jin Quan Street, Fuzhou 350001, China \\ Correspondence should be addressed to Qi-fang Zeng, trpi201111020@gmail.com
}

Received 5 August 2012; Revised 27 September 2012; Accepted 27 September 2012

Academic Editor: Keith E. Holbert

Copyright () 2012 Huang-bin Lin et al. This is an open access article distributed under the Creative Commons Attribution License, which permits unrestricted use, distribution, and reproduction in any medium, provided the original work is properly cited.

Langmuir Probes attached to plasma-facing components in a Tokamak are used to diagnose high-temperature plasma during fusion experiments. In this work, a finite element model of Langmuir Probe-Cooling Monoblock (LP-CM) is established, and structural analysis of the LP-CM is carried out. The maximum von Mises stress during the $400 \mathrm{~s}$ incident heat flux has been given in detail, and the relationship between the sliding friction coefficient and thermal stress has been investigated systematically. A contact design is employed between Langmuir Probe and Cooling Monoblock, which is an effective method to lower the thermal stress. The thermal stress reaches the peak on the edge of the aluminium oxide ceramic interlayer. The damaged displacement field of the LP-CM has been examined fully, and the maximum global displacement is $0.444 \mathrm{~mm}$.

\section{Introduction}

The Langmuir Probe (LP) [1] is one of the most famous diagnostic tools to measure the plasma parameters, which are especially used in nuclear fusion experiments to derive the electronic temperature of a high temperature ionised gas. The LPs are relatively simple devices, they are fabricated by materials with superior electric and thermal conductivity such as metallics, ceramics, and crystallines [2]. A single LP consists of one or more small metallic electrodes and appropriate insulating layer. During the nuclear fusion experiments, the LP array fixed to the surface of plasma facing components are widely used to measure edge plasma parameters in a tokamak, and the running parameters of center plasma can be derived from these edge parameters. By sweeping the applied voltage on the probe, we can obtain the curve of probe current as a function of probe potential and called classical probe I-V characteristic. The electron temperature, the plasma density, and the plasma potential can be deduced from the characteristic [3-5].
With the plasma temperature increasing, the LP faces more severe thermal etching. Aiming at the future experimental requirements under extreme conditions, the thermodynamic properties is critical to the design of LP since it determines the service lifetime, precision, and stability of the LP. In this paper, in order to satisfy the need of the reliability, numerical experiments on an LP-CM have been carried out by ANSYS. The thermodynamic and displacement fields have been given in this paper. Results show the contact design is an effective method to improve the heat transfer capability and lower the thermal stress of the LP.

\section{Construction, Loading Conditions, and Computational Principle}

This analyzed model includes two parts: Langmuir Probe and Cooling Monoblock (CM). The LP is divided into three parts: top pyrolytic graphite (PG), middle pyrolytic graphite, and bottom Cu block. The Cooling Monoblock 


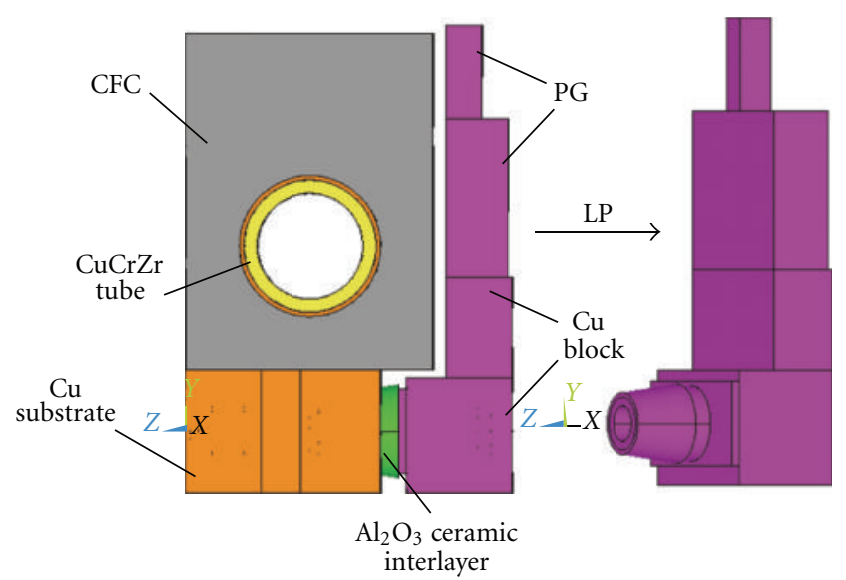

Figure 1: The composition of LP-CM used in structural analysis.

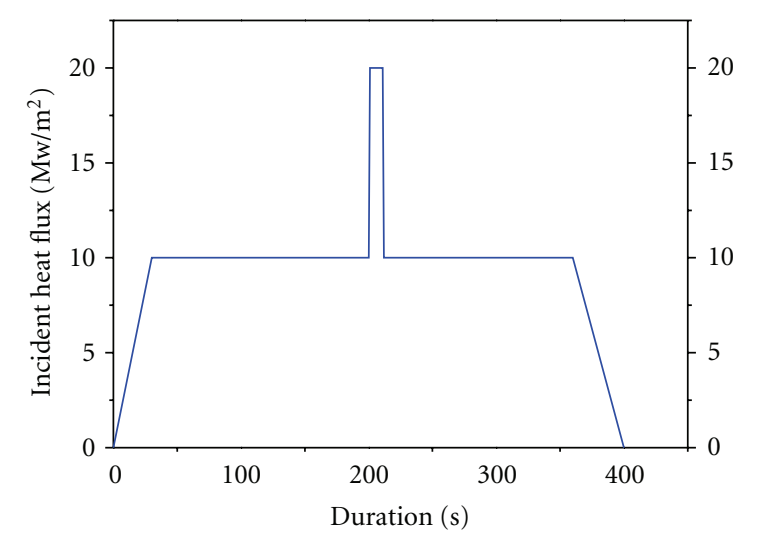

Figure 2: Incident heat flux on analyzed model.

(CM) consists of top carbon fiber composite (CFC) block, cooling $\mathrm{CuCrZr}$ tube, and bottom $\mathrm{Cu}$ substrate, as shown in Figure 1. The PG and CFC are, respectively, soldered to $\mathrm{Cu}$ block and $\mathrm{Cu}$ substrate. The Langmuir Probe is fixed on the Cooling Monoblock by an inconel 718 screw, and a coneshaped $\mathrm{Al}_{2} \mathrm{O}_{3}$ ceramic interlayer (ACI) is inserted between LP and CM for reaching electrical insulation, meanwhile, contact relation lies both between the $\mathrm{Cu}$ substrate and the $\mathrm{ACI}$ and also between the $\mathrm{ACI}$ and the $\mathrm{Cu}$ cone, this is used to obtain higher heat transfer capability and reduce the thermal stress. During the fusion experiment, the LPs are arranged into one circle around the edge plasma in Tokamak and the cooling fluid flows through the center tube of CM for cooling down the device.

A 400 s incident heat flux (IHF) which reflects the energy change of edge plasma is applied on front surfaces, as shown in Figure 2. A $1 \mathrm{MW} / \mathrm{m}^{2}$ steady heat flux is applied on the lateral surfaces of the LP, the thermal convection including heat transfer coefficient HTC $=100 \mathrm{~kW} /\left(\mathrm{m}^{2} \mathrm{~K}\right)$ and cooling temperature of $120^{\circ} \mathrm{C}$ are applied on the inner surfaces of cooling tube. Emissivity factor $\varepsilon=0.5$ is taken in these calculations due to the Stefan-Boltzmann rule. The initial temperature $120^{\circ} \mathrm{C}$ is taken in initial state. Preload force $F_{p}=1200 \mathrm{~N}$ is applied on the bolt. In this

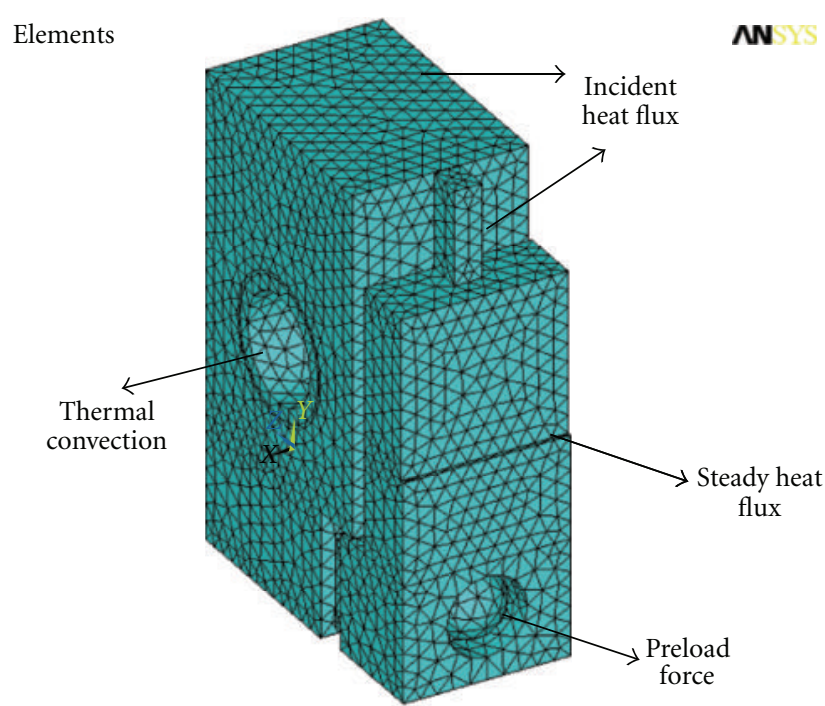

FIGURE 3: The finite element model and thermal loads.

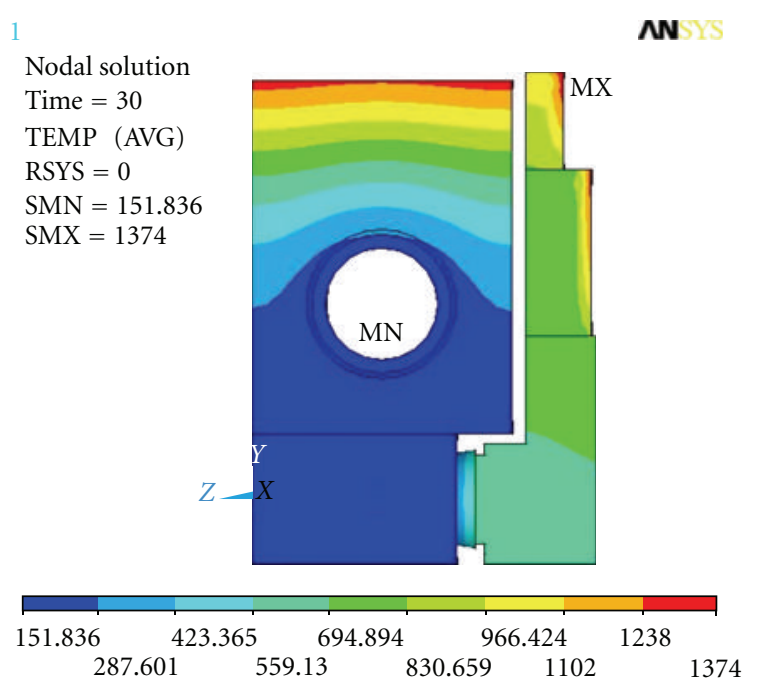

Figure 4: The 30s thermal field of LP-CM.

work, the preload bolt is prepared by prets179 element, the SOLID70 and SOLID45 elements are used to calculate thermal field and thermal stress field, respectively. The mesh model is shown in Figure 3. Temperature-dependent thermal properties such as density, thermal conductivity, and heat capacity are used in this analysis. There are 9 load steps used in this computational process, and a transient-state structural analysis is used to determine the thermodynamic field. The computational method of transient-state analysis is based on the transient-state heat transfer equation, it can be expressed as

$$
[C(T)]\{\dot{T}\}+[K(T)]\{T\}=\{Q(T)\},
$$

where $K(T)$ is the heat conduction coefficient matrix consisting of thermal conductivity, convection coefficient form factor, and emissivity. $C(T)$ is the specific heat capacity 


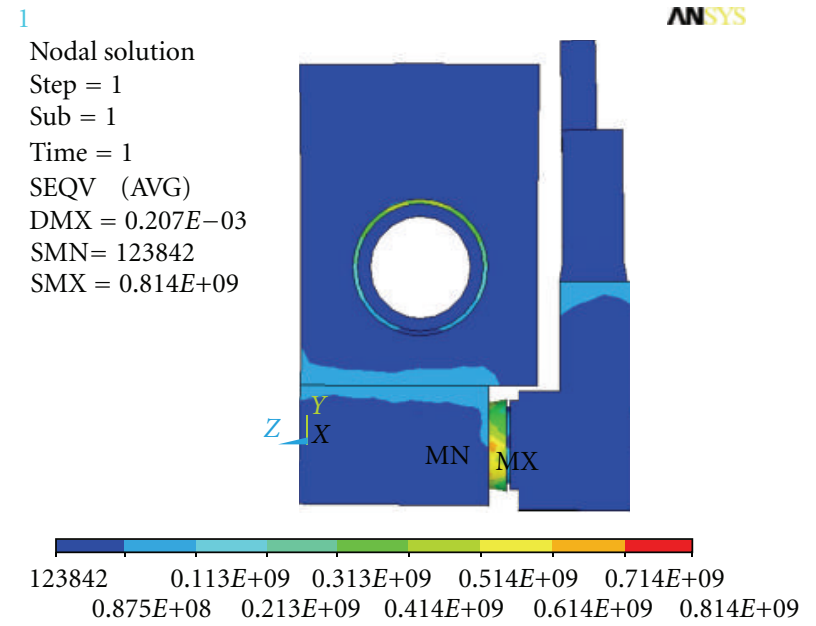

(a)

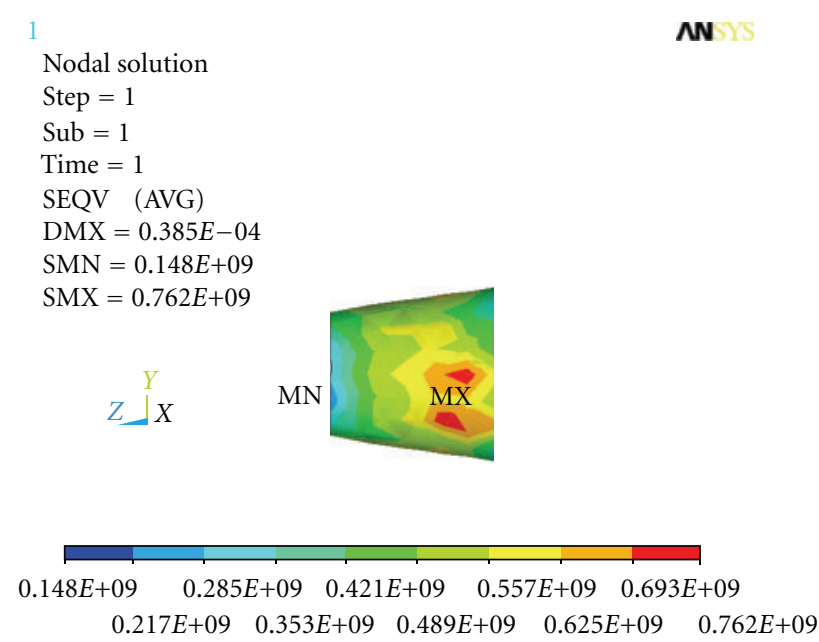

(b)

Figure 5: The $30 \mathrm{~s}$ thermal stress field with contact design: (a) LP-CM and (b) ACI.

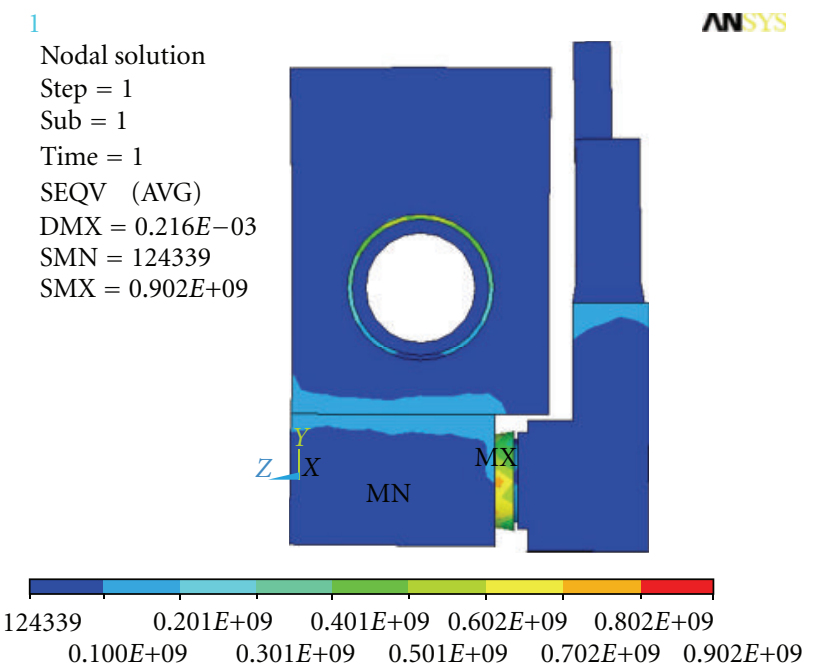

(a)
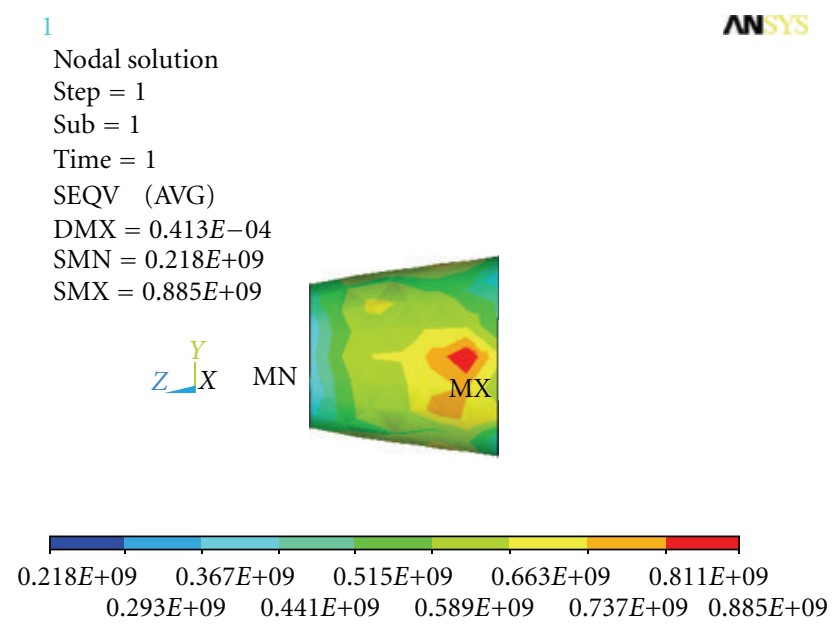

(b)

Figure 6: The $30 \mathrm{~s}$ thermal stress field without contact design: (a) LP-CM and (b) ACI.

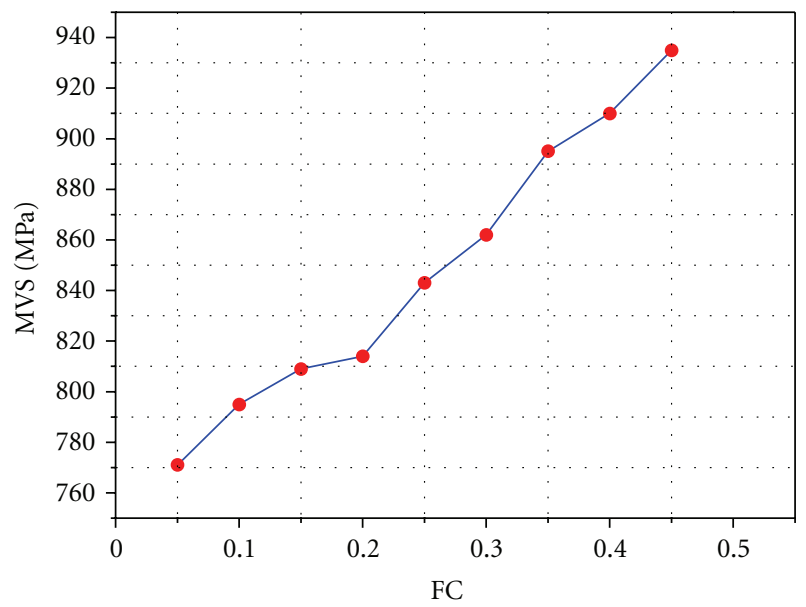

Figure 7: The relationship between sliding friction coefficient and maximum von Mises stress. 


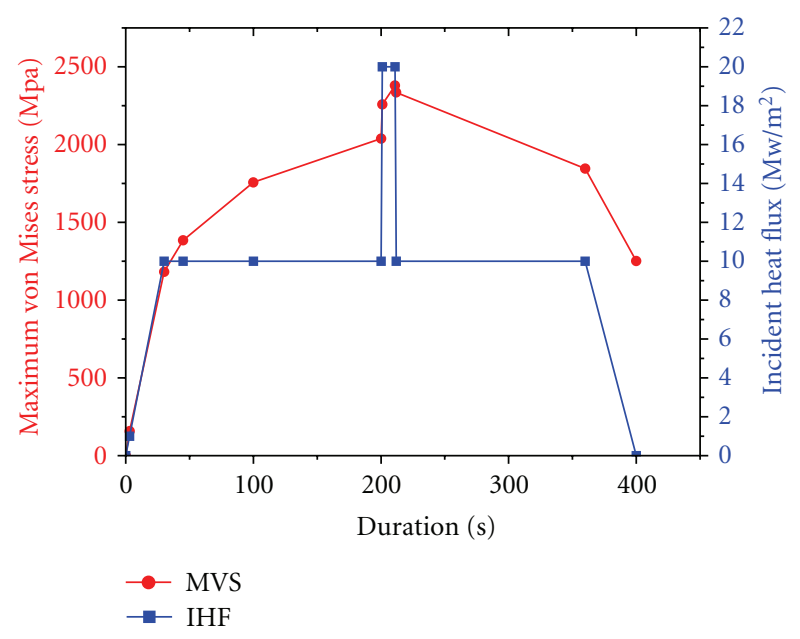

FIGURE 8: The MVS variation tendency during the $400 \mathrm{~s}$ incident heat flux.

matrix, $\{T\}$ is the node temperature vector, $\{\dot{T}\}$ is the time derivative of the nodal temperature, $Q(T)$ is the rate of node heat flow including thermogenesis.

\section{Results and Discussion}

In order to improve the heat transfer capability and lower thermal distortion on the fragile part between the LP and $\mathrm{CM}$, an $\mathrm{Al}_{2} \mathrm{O}_{3}$ ceramic interlayer is inserted between the $\mathrm{Cu}$ substrate and $\mathrm{Cu}$ block as a contact structure, and the LP is attached to the CM via the preload bolt with a preload force of $1200 \mathrm{~N}$. The computational method is based on the classical theory of thermal contact resistance (TCR) at the interface of different materials, its calculation equation can be expressed as

$$
\frac{\sigma}{\rho \mathrm{km}}=1.25\left(\frac{p}{H_{c}}\right)^{0.95},
$$

where $\sigma$ is the surface roughness, $m$ is the absolute surface slope, $\rho$ is the thermal contact resistance, $p$ is the pressure of contact surface, $H_{c}$ is the surface hardness, and $k$ is the harmonic thermal conductivity. The thermal contact resistance can be determined by (2) with measured parameters, the TCR at the $\mathrm{Cu}$ substrate-ACI interface is $3.816 \times$ $10^{-5} \mathrm{~m}^{2} \cdot{ }^{\circ} \mathrm{C} / \mathrm{W}$ and at the Cu block-ACI interface is $3.624 \times$ $10^{-5} \mathrm{~m}^{2} \cdot{ }^{\circ} \mathrm{C} / \mathrm{W}$. The thermal field during the $400 \mathrm{~s}$ incident heat flux is computed by ANSYS, and the $30 \mathrm{~s}$ thermal field of LP-CM are shown in Figure 4. Apparently it shows a gradient temperature distribution from top to bottom, the temperature decreases from $1374^{\circ} \mathrm{C}$ to $152^{\circ} \mathrm{C}$. Moreover, the temperature variation is in accord with the incident heat flux and the temperature reaches the maximum $2608^{\circ} \mathrm{C}$ at 211 s. During the structural analysis, the SOLID70 element must be changed into SOLID 45 element and the thermal field is applied on the model as thermal load. Meanwhile, a sliding friction factor (FC) 0.2 is set between $\mathrm{Cu}$ substrate, $\mathrm{Cu}$ block and ACI [6]. Furthermore, a $1200 \mathrm{~N}$ preload force is applied on the bolt and the two lateral faces of cooling tube are restricted [7]. The thermal stress field at $30 \mathrm{~s}$ is shown in Figure 5.

Obviously, the contact site of different materials exhibits greater thermal stress, especially the ACI needs to withstand larger thermal stress. Clearly the maximum von Mises stress (MVS) is $814 \mathrm{MPa}$, the minimum stress value is $123842 \mathrm{~Pa}$, and the thermal stress on ACI reaches the peak $762 \mathrm{MPa}$, Meanwhile, the thermal stress field without the contact design is shown in Figure 6. It is apparent the MVS lies on the welded part of ACI and Cu block, and the peak $885 \mathrm{MPa}$ is obtained at the edge of $\mathrm{Al}_{2} \mathrm{O}_{3}$ ceramic interlayer. Comparing Figure 5 with Figure 6, clear difference can be observed which shows the thermal stress on ACI in Figure 6 is much larger than that in Figure 5. This implies that the contact design between different materials may not only play a role of insulation, but also decrease the thermal stress drastically. Appropriate relative slide at contact site is helpful to reduce the thermal stress. The contact tightness is regulated by the FC in finite element analysis. We have figured out the numerical relationship between FC and MVS, and it is shown in Figure 7. Obviously the MVS is proportionate to the FC, that means the increasing of frictional resistance leads to an increase of thermal stress, however, too much decreasing of FC will bring a huge increasing of TCR, hence, there must be an optimum FC value to obtain the minimum stress.

The thermal stress during the incident heat flux are figured out by ANSYS and the MVS value at different times is shown in Figure 8. Clearly the MVS shows a variation tendency from increasing to decreasing with the incident heat flux and reaches the peak $2380 \mathrm{MPa}$ at $211 \mathrm{~s}$, where the peak temperature is obtained at this moment, the $211 \mathrm{~s}$ thermal stress field is shown in Figure 9. The $211 \mathrm{~s}$ displacement field is shown in Figure 10. Figure 10(a) shows the maximum global displacement consists of the connection part of PG and $\mathrm{Cu}$ block, and almost reaches $0.444 \mathrm{~mm}$. The maximum $X$-displacement, $Y$-displacement, and $Z$ displacement at $211 \mathrm{~s}$ are, respectively, $0.155 \mathrm{~mm}, 0.326 \mathrm{~mm}$, and $0.867 \mathrm{~mm}$.

\section{Conclusions}

An improved LP-CM model was established, and transientstate structural analysis used to predict the thermodynamic state of LP-CM was carried out by ANSYS. The thermal stress field and displacement field have been given in this paper. Results show that the thermal stress becomes increasing at the interface of different material. ACI probably is the most vulnerable place because of the maximum thermal stress acting on it, and the LP-CM with a contact structure presents lower thermal stress than the LP-CM without contact structure. The thermal stress reaches the peak $762 \mathrm{MPa}$ on the edge of ACI under the contact state. The maximum thermal stress has a positive correlation with FC and there must be an optimum FC value to obtain the minimum stress. The $211 \mathrm{~s}$ global displacement field shows that the maximum displacement $0.444 \mathrm{~mm}$ consists in the connection part of PG and $\mathrm{Cu}$ block. The findings could provide useful information to develop high-performance Langmuir Probe. 


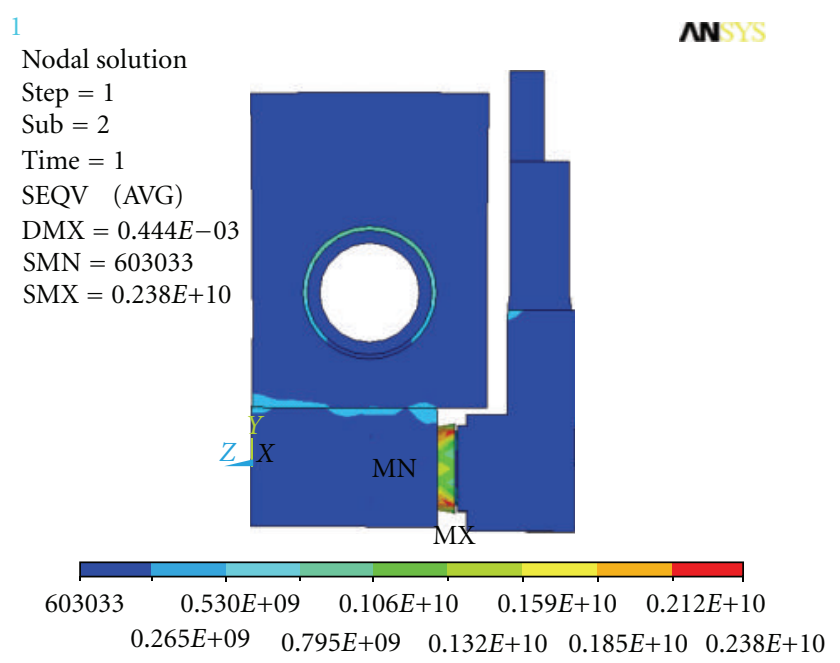

(a)

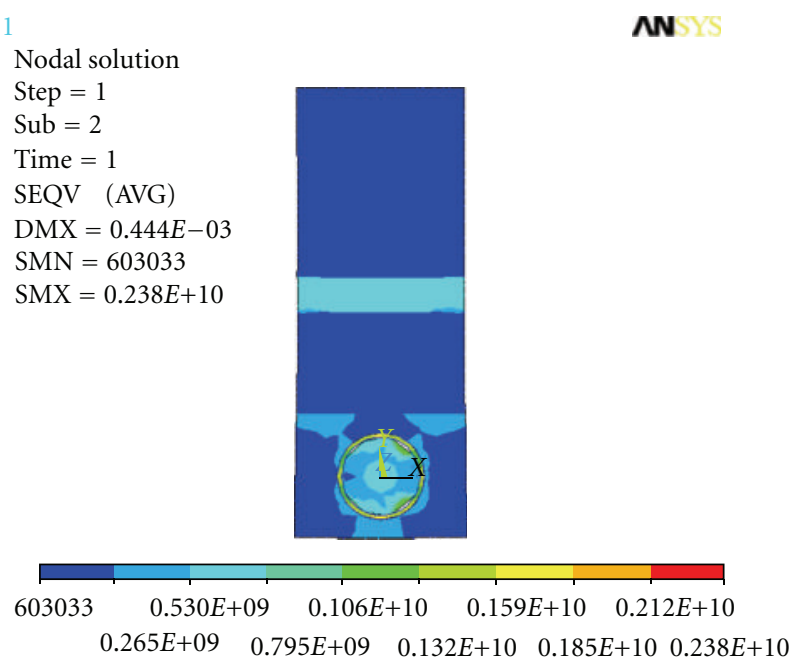

(b)

Figure 9: The $211 \mathrm{~s}$ thermal stress field of LP-CM (a) front view and (b) cross section.

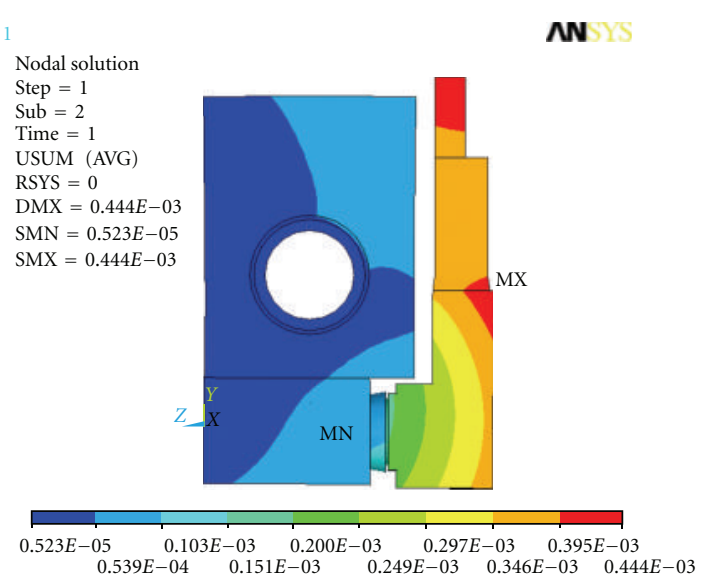

(a)

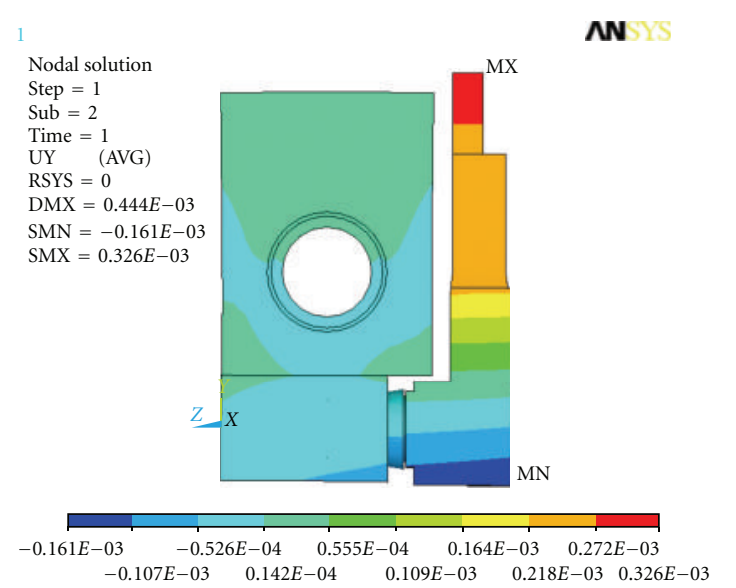

(c)

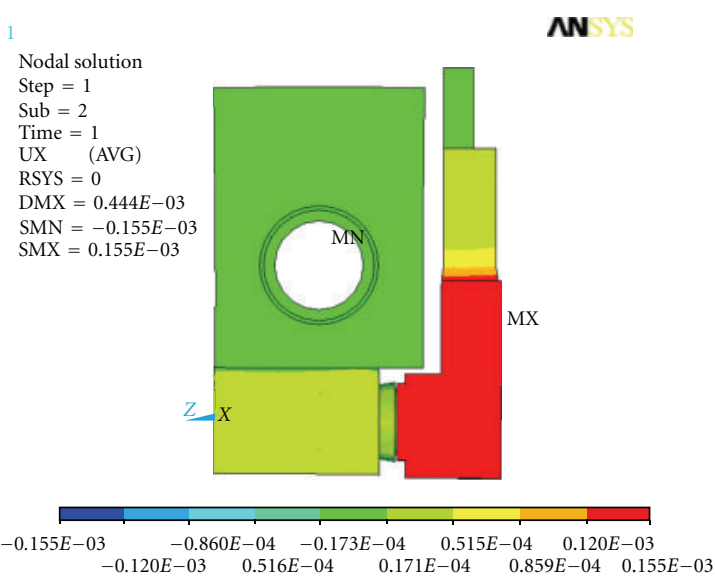

(b)

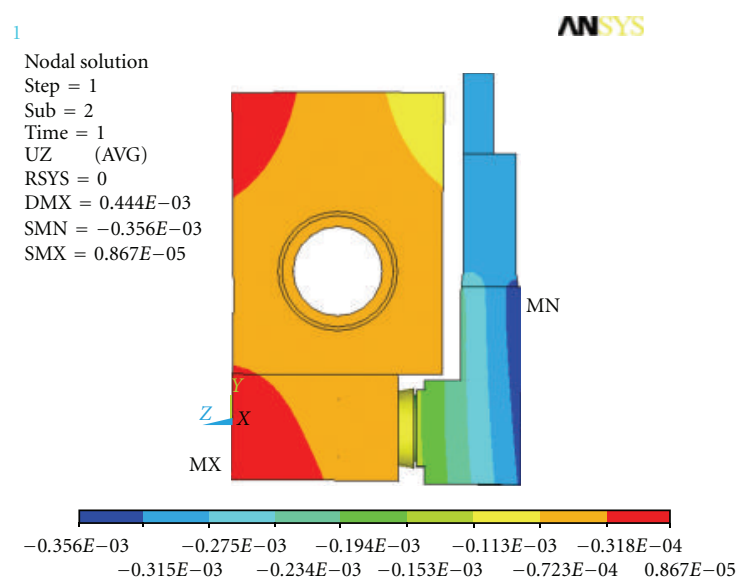

(d)

Figure 10: The displacement field at $211 \mathrm{~s}$ : (a) global displacement, (b) $X$-displacement, (c) $Y$-displacement, and (d) $Z$-displacement. 


\section{Acknowledgments}

This work is supported by National Special Fund for the Territorial Resources in the Public Interest (no. 201111020-

2), Natural Science Foundation of Fujian Province of China (Grant no. 2011J01320), Foundation of Overseas Chinese Affairs Office of the State Council for Huaqiao University (no. 11QZR15), and Fundamental Research Funds for the Central Universities.

\section{References}

[1] I. H. Hutchinson, Principles of Plasma Diagnostics, Cambridge University Press, Cambridge, UK, 2nd edition, 2002.

[2] W. E. Amatucci, P. W. Schuck, D. N. Walker et al., "Contamination-free sounding rocket Langmuir probe," Review of Scientific Instruments, vol. 72, no. 4, pp. 2052-2057, 2001.

[3] P. C. Stangeby, "Effect of bias on trapping probes and bolometers for Tokamak edge diagnosis," Journal of Physics D, vol. 15, p. 1007, 1982.

[4] R. Schrittwieser, JiríAdámek, P. Balan et al., "Measurements with an emissive probe in the CASTOR tokamak," Plasma Physics and Controlled Fusion, vol. 44, pp. 567-578, 2002.

[5] M. Bagatin, D. Desideri, E. Marlines, G. Manduchi, G. Serianni, and V. Antoni, "Automatic fast fitting of single Langmuir probe characteristics on RFX," Review of Scientific Instruments, vol. 68, no. 1, pp. 365-368, 1997.

[6] ANSYS Contact Technology Guide Section 6. 1.4.1.

[7] N. Hartman and R. A. Rimmer, "Electromagnetic, thermal, and structural analysis of RF cavities using ANSYS," in Proceedings of the Particle Accelerator Conference (PAC '01), pp. 912-914, Chicago, Ill, USA, June 2001. 

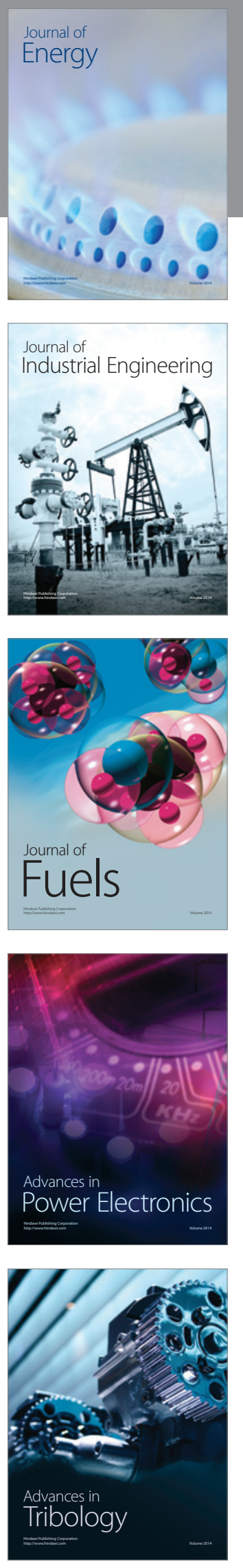
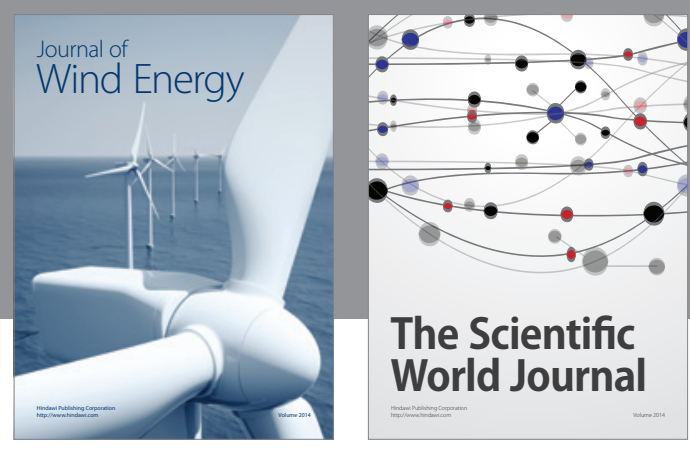

The Scientific World Journal

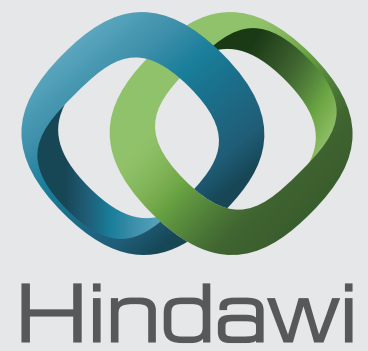

Submit your manuscripts at http://www.hindawi.com
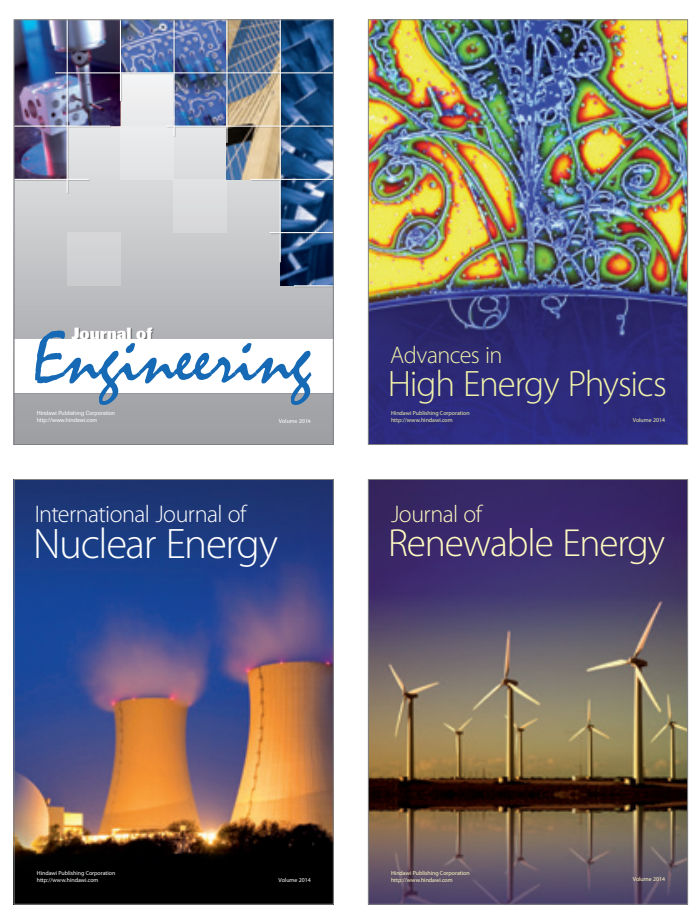

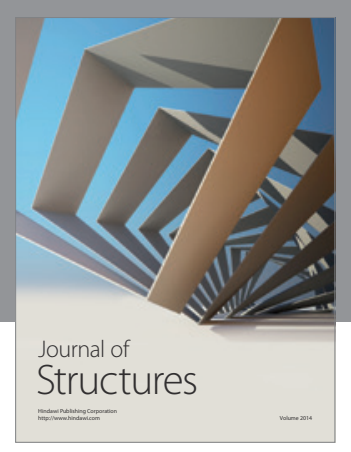

Rotating
Mechinery
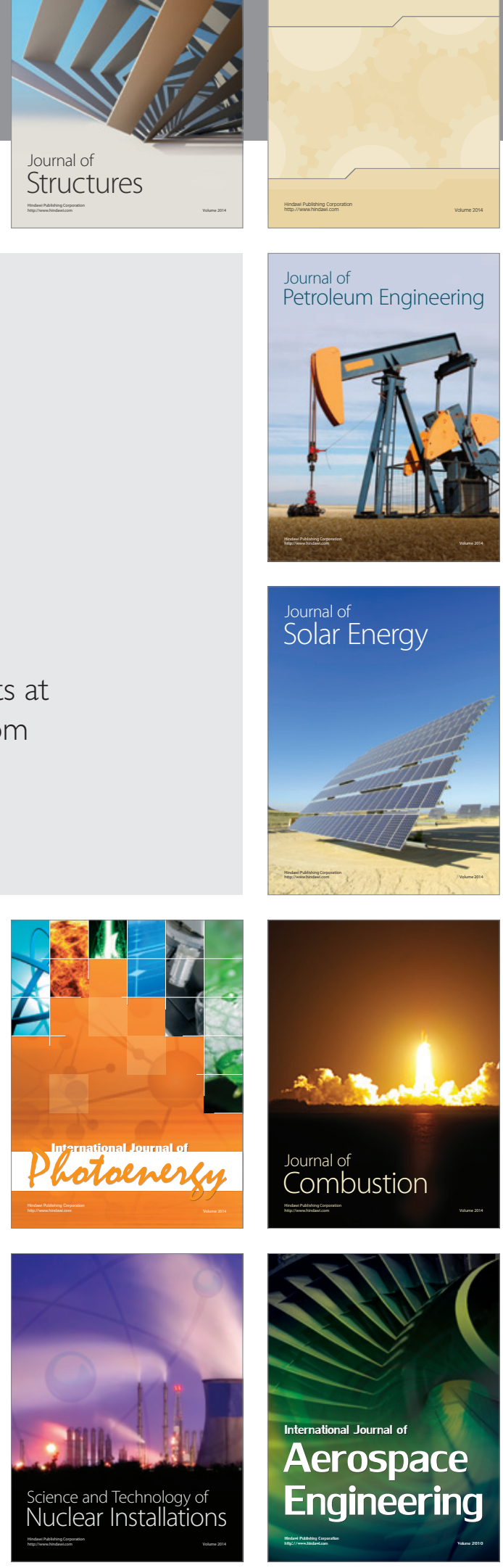